\title{
¿"UNA MISMA COSA CON LA VUESTRA"?: \\ ERCILLA, PEDRO DE OÑA Y LA APROPIACIÓN POST-COLONIAL \\ DE LA PATRIA ARAUCANA
}

POR

\author{
Roberto Castillo Sandoval \\ Haverford College
}

\begin{abstract}
no somos Europeos, no somos Indios, sino una especie media entre los Aborígenes y los Españoles. Americanos por nacimiento y Europeos por derechos, nos hallamos en el conflicto de disputar a los naturales los títulos de posesión y de mantenernos en el país que nos vio nacer ...; así nuestro caso es el más extraordinario y complicado.

Simón Bolívar, "Discurso de Angostura" Escritos políticos 96
\end{abstract}

La última batalla de las guerras de Arauco, librada en 1883, culminó con la derrota de los indígenas y la ocupación de las ruinas del lugar donde más de tres siglos antes, en 1552, Pedro de Valdivia y sus conquistadores habían fundado el pueblo de Villarrica. Entre los vencedores de la jornada aparece el nombre de "Caupolicán". No se trata, evidentemente, del célebre héroe araucano, ni tampoco de algún jefe mapuche que descendiera de él, sino de un batallón del ejército de la República de Chile, formado por veteranos fogueados en la recién concluída Guerra del Pacífico contra Perú y Bolivia. El batallón "Caupolicán" no era, ni mucho menos, el único cuerpo armado chileno bautizado en homenaje a los héroes del poema de Ercilla. Por esa misma época, con un dejo de asombro y resignación, Domingo F. Sarmiento comenta el surgimiento de una verdadera onomástica erciliana dentro de la cultura chilena:

La historia de Chile está calcada sobre la Araucana, y los chilenos, que debían reputarse vencidos con los españoles, se revisten de las glorias de los araucanos á fuer de chilenos estos y dan á sus más valientes tercios ... y á sus naves [los nombres] de Lautaro, Colocolo, Tucapel, etc. Y creemos que estas adopciones han sido benéficas para formar el carácter guerrero de los chilenos, como se ha visto en la guerra reciente con el Perú (Conflictos y armonias 49).

El desplazamiento onomástico que permite bautizar al chileno patriota con el nombre del araucano heroico va acompañado de una transferencia análoga entre la República de Chile y el territorio de Arauco: así como el nombre de Caupolicán es definitivamente 
chilenizado, la Araucanía es apropiada y sustituida por Chile. Arauco y Chile son los elementos territoriales de la tensa ecuación ideológica que se remonta a Ercilla, la que puede ser resuelta al lograrse por fin la posesión efectiva de la Araucanía y la capitulación de sus rebeldes habitantes. Horacio Lara, cronista chileno de la última guerra de la Araucanía, describe diáfanamente los términos y los alcances de la transacción de nombres:

con la ocupacion de Villa-Rica había llegado el último dia de existencia para Arauco (460); quedaba borrada para siempre de nuestro mapa aquella seccion territorial ... La Araucanía desaparecia, pues del todo (Crónica de la Araucanía 464, énfasis mío).

La república de Chile, en efecto, borra a la Araucanía con una conquista militar cuyos emblemas - procedentes a todas luces del mito erciliano- hacen posible que la ocupación se represente como si fuera de verdad una recuperación. El "Caupolicán" chileno, también conocido como el regimiento de los "soldados-obreros", reconquista un territorio a cuya posesión tiene derecho en virtud de su demostrado valor guerrero y su ferviente amor a la patria. ${ }^{1}$ El panegirista de la reconquista chilena habla de Villarrica, llamada "la ciudad de las ruinas", en términos que despiertan en los oídos del lector contemporáneo las resonancias de la invocación que haría Neruda frente a los restos de otra ciudad perdida en el tiempo, en "Alturas de Machu Picchu”. Pero la invocación de Lara tiene un sentido diametralmente opuesto a la del poeta del Canto general: es el pasado hispano que renace después de haber estado sepultado por la historia de dominación territorial indígena:

Renacerá de sus cenizas la opulenta Villa-Rica, la infortunada ciudad de Pedro de Valdivia ...; renacerá, sí, la ciudad famosa, i descorrerá el denso velo que por trescientos años ocultaba sus infortunios, ... esperando adorm[ec]ida en el augusto osario de sus solemnes ruinas el jenio providencial que alguna vez descendiera a ella i le dijera solícito: "Lázaro, levántate, $i$ anda" (451).

En efecto, la Villarrica fundada por Valdivia "sube a nacer" al ser rescatada por el regimiento Caupolicán, mientras que Arauco se convierte, como contrapartida, en "tumba inmensa", como lo llama Eduardo de la Barra en un poema seudo-elegíaco de la época,

\footnotetext{
${ }^{1}$ El estrato social bajo, mayormente mestizo, aparece asociado desde temprano con la ambivalente imagen erciliana del araucano. La figura emblemática del "roto chileno" está hecha a base de una mezcla de idealización y reticencia análoga a la que Ercilla usara para retratar al araucano. Enrique Solar Correa afirma que "todos los Caupolicanes, las Fresias, las Tegualdas que circulan por nuestras calles reconocen como auténtico padrino a nuestro poeta .... En Chile respiramos a Ercilla y no lo sabemos" (Semblanzas literarias de la colonia 45-48). Orrego Luco, por su parte, realiza una ostensible igualación en su descripción del "roto": "Fuerte, resistente para el trabajo, robusto i capaz, al mismo tiempo, de las mayores privaciones y fatigas, es aficionado a la embriaguez, a menudo dado al robo, aficionado a las rifras. Dotado de la supersticion en que lo sumian su ignorancia i la herencia de las preocupaciones españolas, tiene la valentia i el empuje del indio araucano" ("Las jerarquías sociales" 41). Previsiblemente, los defectos de los araucanos no son compartidos por el segmento de la población que Orrego Luco denomina "la clase criolla", en quienes, sin embargo, dice que "existia un amor ardiente al suelo de la patria, unido a la creencia de que el país no era superado por ningún otro en riqueza, en fertilidad, en hermosura, ni en progreso" (41).
} 
aptamente titulado "La Araucana" (“Ay de mí, ay de mí/ Ya se acabó mi tierra! Arauco ya no existe!"). Con la obliteración de toda señal de resistencia por parte de los indígenas mapuches, éstos pasan a ser en efecto una suerte de "ex-araucanos": en su derrota son despojados definitivamente de todas sus antiguas cualidades míticas, de las que toman posesión, junto con el territorio, los oficiales criollos triunfadores y sus soldados mestizos. Lara narra así la clausura del parlamento final entre chilenos y araucanos:

La banda de música rompió con la canción nacional; y habiéndoseles advertido a los [indios] que ese himno era la canción guerrera de los chilenos, lanzaron un estruendoso grito de ¡Viva Chile! (451).

Llega aquí a un punto culminante la pugna simbólica por igualar Arauco y Chile, en la cual se enraiza la identidad nacional adoptada por los criollos chilenos. Sin embargo, el mito erciliano "en bruto" presenta un antagonismo virtualmente insubsanable entre españoles y araucanos, antagonismo que no es enteramente congruente con la igualación de signo positivo entre Chile y la Araucanía que se concreta con el triunfo simbólico del "Caupolicán" en Villarrica. Para encontrar la pista del mecanismo que permite representar la derrota y el desplazamiento del indígena mapuche por medio de un triunfo del araucano mítico ("Caupolicán"), será necesario considerar la elaboración posterior del mito erciliano a manos de criollos como Pedro de Oña. Esta elaboración, centrada en torno al problema del dominio del territorio patrio, sí podría explicar la dinámica discursiva que permite y necesita - la derrota del pueblo mapuche a manos del chileno decimonónico en guisa de Caupolicán.

La fortuna crítica de los dos poemas épicos principales que versan sobre las guerras de Arauco encierra una paradoja. Por una parte, el español Ercilla y su obra han sido ubicados desde muy temprano en un lugar francamente privilegiado dentro de la literatura, la historiografía y esa entidad nebulosa a veces denominada la "cultura chilena".2 El gesto temprano de acudir a la imagen del araucano ficticio cobró fuerza en la historiografia y la literatura chilena hasta convertirse en el mito fundacional por excelencia, el lugar de la imaginación donde se gesta la fusión de los dos componentes vitales de la nacionalidad que recién emerge. Este proceso de canonización de La Araucana alcanza su punto culminante en la reelaboración poética llevada a cabo por Pablo Neruda en su Canto general, en el cual el legado poético de Ercilla es vertido plenamente dentro de un discurso de reivindicación americanista. El Ercilla de Neruda incluso posee el don de la

${ }^{2}$ La Araucana ya era una piedra angular del discurso patriótico chileno aun antes de que Bello la canonizara como la Eneida de la joven nación. Incluso en la etapa que podríamos denominar prehistoriográfica de la república (es decir, antes de que el científico francés Claudio Gay sacara a luz la primera historia de Chile) se encuentran muestras de la utilización del panteón mítico inventado por Ercilla en El chileno instruido en la historia topográfica, civil y política de su país se encuentra el siguiente diálogo: "Sob[rino]: Hubiera conocido yo de buena gana a este valeroso jóven chileno Lautaro. Tío: Ya eso es imposible: imítale en el patriotismo, y serás aplaudido como él" (176). El abate Ignacio de Molina, de cuyas páginas el autor del Chileno instruído saca su información, había utilizado ya La Araucana como puntal de autoridad de su compendio, no necesariamente como fuente documental, sino como modelo de caracterización del habitante de Arauco. 
clarividencia histórica, que le permite discernir algo nuevo e insólito en la realidad que enfrenta durante su fugaz paso por Arauco:

\author{
Él solamente solo nos descubrió a nosotros: \\ sólo este abundante palomo \\ se enmarańó en nosotros hasta ahora \\ y nos dejó en su testamento \\ un duradero amor ensangrentado.
}

Muy diferente ha sido la historia de la recepción del Arauco domado de Pedro de Oña, a pesar de que se le reconoce, como lo hace Lastarria en su famoso discurso de inauguración de la Sociedad Literaria, el vacuo mérito de ser el primer poeta nacido en el suelo patrio. ${ }^{3}$ Mientras que Ercilla es admirado por su caracterización ideal del contrincante araucano, la obra de Oña ha sido criticada abierta o implícitamente por su esfuerzo de halagar al bando español representado en la figura de García Hurtado de Mendoza, a quien Ercilla colgara el baldón de "mozo capitán acelerado". La figura de Oña es para muchos el emblema de una mentalidad colonizada polarmente opuesta a la de un Ercilla supuestamente esclarecido y anticolonialista. ${ }^{4}$ Pero a pesar de que la supuesta igualación heroica entre indios y españoles de La Araucana pareciera darle al poema la virtud de la inclusividad, creemos que es en la obra de Oña donde se revelan con mayor profundidad las voces de todos los protagonistas de la pugna por el territorio de América, pugna tan íntimamente ligada al problema de la identidad nacional y continental, como lo expresa con lucidez el criollo americano por excelencia en el epígrafe que encabeza estas páginas.

La apropiación política de La Araucana no es nada nuevo en la cultura chilena. Andrés Bello ya veía en este poema un "sentimiento dominante ... de una especie más noble: el amor a la humanidad, el culto a la justicia, una admiración generosa al patriotismo y denuedo de los vencidos" ("La Araucana de don Alonso de Ercilla y Zúñiga" 360), sentimiento que Bello adjudica principalmente a los españoles, en quienes quiere ver a los más legítimos ancestros de los chilenos. En el siglo XX, esta apropiación se refleja en la reevaluación no sólo del poema, sino de la figura misma del autor, a quien se le llega a atribuir una conciencia de la posibilidad de una lectura "americana" y subversiva

\footnotetext{
${ }^{3}$ Lastarria se refiere al poeta angolino así: "Pedro de Ona, que según las noticias de algunos eruditos, escribió a fines del siglo XVI dos poemas de poco mérito literario, pero tan curiosos como raros en el dia; el célebre Lacunza, Ovalle el historiador i el candoroso Molina ... son los cuatro conciudadanos, i quizá los únicos de mérito, que puedo citaros como escritores; pero sus producciones no son timbres de nuestra literatura, porque fueron indijenas de otro suelo i recibieron la influencia de preceptos estranos.(Recuerdos literarios 17).

${ }^{4}$ En palabras de los traductores al inglés del Arauco domado: "Ercilla is the spokesman of the Araucanian Indians, and his work, as in a high tribunal, stands against the strictly Spanish viewpoint of Ona, a native Chilean" (Charles Maxwell Lancaster y Paul T. Manchester, Arauco Tamed 15) 0 en las más recientes de un crítico chileno: "Ona fue un artista de mentalidad colonial que no presintió para nada el destino de América" (René Jara, El revés de la arpillera 26).
} 
de su obra. Esta última lectura, de signo político de izquierda, ha perpetuado la percepción (también propugnada por sectores nacionalistas a la derecha del espectro político) de que el germen de la identidad nacional chilena se encuentra representado en el poema de Ercilla. Desde esta perspectiva, se configura una Araucana en la que lo que prevalece no es la nobleza del conquistador, sino la imagen positiva del indígena derrotado, presentada por un autor crítico. Fernando Alegría lo expresaba así en 1954:

Ercilla ... interpretó justamente lo que para nuestro continente constituye en un momento de su historia el tema épico por excelencia: la lucha por la libertad económica y política contra los imperialismos extranjeros ... el poeta no es ya el mero cronista, sino el activo militante que une su esfuerzo al del pueblo para hacer historia (La poesía chilena: origenes y desarrollo del siglo XVI al XIX 40-41, énfasis mío).

Esta lectura destaca primordialmente dos aspectos del poema: la contraposición de los falibles españoles con la imagen enaltecida de los araucanos, y el esfuerzo por representar la lucha de este pueblo al nivel de las grandes epopeyas occidentales, afán que movería los variados mecanismos de mitificación empleados por Ercilla (Beatriz Pastor, Discurso narrativo de la conquista de América 494-519). Tal interpretación, en mayor o menor grado, requiere soslayar el lado negativo del retrato del araucano para sostener una idea de Ercilla como defensor del araucano o bien como crítico de la conquista. ${ }^{5}$ Debido a la preponderancia del gesto de volver la mirada a Ercilla como fuente de la identidad patria, queda indebidamente oscurecida la complejidad de la recepción que La Araucana tuvo entre criollos como Oña, grupo social que se haría protagonista del proyecto nacional chileno después de la independencia y que encabezaría la apropiación territorial definitiva de la Araucanía. ${ }^{6}$

\section{Locus amoenus vs. tierra maldita: el Arauco enemigo de Ercilla}

Si bien es cierto que en ocasiones Ercilla utiliza "Chile" y "Arauco" como términos intercambiables, en La Araucana se ve una constante separación entre el ámbito cultural

\footnotetext{
${ }^{5}$ Francisco Javier Cevallos ha planteado muy acertadamente que "Ercillaís view of the Indians is inconsistent", y más aún, que "the 'real' Araucanians are not depicted in such positive and heroic way" ("Don Alonso de Ercilla and the American Indian: History and Myth" 17, énfasis mío). La motivación de Cevallos es la de establecer el carácter literario del poema - "a Spanish poem of the European Renaissance"- mientras que en estas líneas se pretende expandir lo innegablemente literario hacia el plano de la recepción del poema y su influencia como fuente de imágenes germinales en el discurso de la nacionalidad chilena. Otra manera de caracterizar lo que Cevallos ve como "inconsistent" es la de oscilante. Acotemos aquí también que así como Ercilla ha sido leído como defensor del araucano, Pedro de Oña ha sido acusado de tener una mentalidad demasiado "colonizada" para un criollo. Véase Mario Rodríguez, "Un caso de imaginación colonizada: Arauco domado", Acta literaria 6 (1981): 79-92.

${ }^{6}$ Véase al respecto el trabajo de Mario Góngora, Ensayo histórico sobre la noción de Estado en Chile en los siglos $X I X y X X$, y Roberto Castillo Sandoval, "Remedios para el 'embrollado laberinto' de Arauco: Barros Arana y el lugar del Cautiverio feliz en la historiografia de Chile", a publicarse.
} 
y territorial de los españoles (generalmente llamado Chile) y el de los araucanos, el "Estado que tanta sangre ajena y propia cuesta/ ... que tuvo a Chile en tal estrecho puesta" (La Araucana, I, I, 11). Lejos de confundirse, Chile y el Estado araucano son entidades que se repelen mutuamente y cuyo contacto inevitablemente conduce a la confrontación violenta:

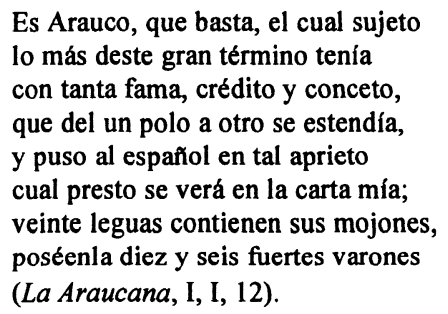

Desde su descubrimiento, la caracterización de la tierra de Chile había oscilado entre la imagen de "tierra maldita" cuya naturaleza hostil derrota la primera expedición de Diego de Almagro, y la de cornucopia exaltada tan elocuentemente por Pedro de Valdivia en su segunda carta a Carlos V. ${ }^{7}$ Pero en La Araucana la descripción del territorio no se refiere solamente a sus cualidades naturales, sino que se lo vincula con la transformación que sufre a manos de sus habitantes indígenas. Desde el Canto I comienza un ambivalente vaivén descriptivo del territorio, acompañado con frecuencia de la presencia de los indígenas. En la octava 38 Ercilla describe el lugar en que se reúne el concilio araucano con imágenes bucólicas y armoniosas; pero ya en la siguiente estrofa se dice que este locus amoenus no es un paraje netamente natural, sino que ha sido escogido, diseñado y modificado por sus habitantes:

Hácese este concilio en un gracioso
asiento de mil florestas escogido,
donde se muestra el campo más hermoso
de infinidad de flores guarnecido:
allí de un viento fresco y amoroso
los árboles se mueven con ruido,
cruzando muchas veces por el prado
un claro arroyo limpio y sosegado,
do una fresca y altísima alameda
por orden y artificio tienen puesta (La Araucana, I, I, 38-39, énfasis mío).

\footnotetext{
${ }^{7}$ Valdivia escribe: “... porque esta tierra es tal que para poder vivir en ella y perpetuarse no la hay mejor en el mundo ódígolo porque es muy llana, sanísima, de mucho contento; tiene cuatro meses de invierno no más, que en ellos, si no es cuando hace cuarto la luna, que llueve un día o dos, todos los demás hacen tan lindos soles, que no hay para qué llegarse al fuego ... que parece la crió Dios a posta para tenerlo todo a mano" ("Cartas de relación de la conquista de Chile" 43-44). Véase Lucía Invernizzi, "La representación de la tierra de Chile en cinco textos de los siglos XVI y XVII".
} 
Pero inmediatamente el poeta matiza la imagen idílica mediante la caracterización negativa del nativo: "Gente es sin Dios ni ley, aunque respeta/ aquel que fue del cielo derribado,/ que como poderoso y gran profeta/ es siempre en sus cantares celebrado" (La Araucana, I, I, 40). Esta alusión demoníaca es constante, y se encuentra a menudo ligada a la valentía - virtud principal del araucano- que resulta así denigrada de manera fundamental $(I, I, 41)$. En la octava 45 concluye:

En fin, el hado y clima de esta tierra, si su estrella y pronósticos se miran, es contienda, furor, discordia, guerra y a solo esto los ánimos aspiran; todo su bien y mal aquí se encierra: sus hombres que de súbito se aíran, de condición feroces, impacientes, amigos de domar estrañas gentes.

En ocasiones, la visión idealizada no contrasta de manera secuencial o directa con su matización o negación, lo que no impide que sea igualmente efectiva o válida. La descripción del dulce paraje que acabamos de citar, por ejemplo, tiene su contrapartida en una macabra escena de celebración guerrera que aparece más adelante. La utilería de esa primera escena idílica del concilio se repite, pero esta vez sus elementos se ven sometidos a una siniestra transformación:

Cuando la luz las aves anunciaban
y alegres sus cantares repetían,
un sitio de altos árboles cercaban,
que una espaciosa plaza contenían,
y en ellos las cabezas empalaban
que de españoles cuerpos dividían;
los troncos, de su rama despojados,
eran de los despojos adornados (I, III, 73).

Un ejemplo más de esta degradación del paisaje bucólico por la acción bárbara de los araucanos se encuentra en el canto VI, donde se narra la masacre de la cuesta de Andalicán, escenario del episodio menos heroico de toda la guerra:

A la siniestra mano hacia el poniente estaban dos caminos mal usados; éstos debian ser antiguamente por do al agua bajaban los venados. Digo en tiempos pasados, que al presente por mil partes estaban derrumbados y el remate tajado con un salto de más de ciento y veinte brazas de alto (I, VI, 45, énfasis mío). 
Los parajes ideales de Arauco han sido transformados en artificiales jardines malignos -demoníacos- mediante la acción de sus belicosos habitantes. ${ }^{8}$ Estas descripciones del paisaje, entrelazadas con la acción que en ellas se desarrolla, conllevan una evidente función caracterizadora; más allá de la literaridad que le inyectan al texto, son portadoras de un contenido ideológico difícil de ignorar: esos habitantes no son plenamente merecedores de vivir en un suelo como ése, al que han vilificado con su barbarie y en el cual permanecen sólo en virtud de su sobrehumano ímpetu guerrero. En vista de esta caracterización oscilante, si se ha de hablar de la supuesta "restitución" de humanidad al sujeto americano, como propone con destreza Beatriz Pastor, también es propio referirse con un grado similar de atención a las maniobras de destitución moral que Ercilla realiza con respecto a los araucanos de su poema. ${ }^{9}$ Una lectura desapasionada no debe soslayar el hecho de que la innegable idealización tiene como contrapartida constante y sistemática la homologación del araucano como bárbaro y como enemigo. ${ }^{10}$ Esta lectura reduccionista del retrato del enemigo indio en La Araucana impide ver que en virtud a la potencia del legado de Ercilla, la primera incorporación de la figura del araucano a la idea de patria en Chile no contiene ni pura idealización ni denigración, sino una oscilante adjudicación de ideal y barbarie. " En un gesto que marcará profundamente la visión criolla del araucano,

\footnotetext{
${ }^{8}$ Rosa Perelmuter-Pérez ha observado, en un trabajo en que las descripciones idílicas son vistas como "interludios" entre acciones bélicas según la tradición épica renacentista, que "el jardín de Fitón ... no es sino un paraíso falso" ("El paisaje idealizado en La Araucana" 138).

9 El énfasis exclusivo en la "humanización" del araucano parece enraizarse en un afán crítico por asentar la figura de Ercilla en oposición al bando "colono depredador" (Pastor 508; Durand 133-34). Es justo señalar, sin embargo, que las afirmaciones de José Durand están enmarcadas en su esfuerzo por detallar aquellas rivalidades estamentarias - chapetones contra baquianos- que se fueron desarrollando con el transcurso de la guerra de conquista dentro del bando español, por establecer cómo tales pugnas se revelan en el poema y cuál es la postura que asume frente a ellas el soldado Ercilla. Digna de ser destacada por su acuciosidad es su labor de ligar la supuesta "actitud proindígena de Don Alonso" a su contacto con las ideas de Vitoria y Las Casas ("El chapetón Ercilla y la honra araucana" 117-121). Durán afirma: "La actitud fundamental de honrar a unos héroes bárbaros se nutre de los grandes debates lascasianos sobre la dignidad humana de esos indios y la justicia de esas guerras: ideas respiradas a diario en la vida chilena, o en Lima, o en la Corte" ("Caupolicán, clave historial y épica de La Araucana" 373). Pero para que este enfoque sea posible, reiteramos, Durand también debe pasar por alto el otro lado del retrato del araucano.

${ }^{10}$ No podemos dejar de señalar aquí las palabras de Rolena Adorno frente al favor crítico - con sus claras implicaciones políticas - que Bernal Díaz del Castillo ha sido capaz de generar en su pugna con Gómara y Cortés: "To make Bernal a hero of the conquest and a hero of conquest historiography, to allow him to 'win' by general acclamation over Gómara a battle of the pen and over Cortés a battle for fame is, in fact, to be seduced by Bernal's own efforts at rhetorical persuasion -a rhetorical persuasion which is one of the truest- and obviously, most far-reaching achievements" ("Discourses on Colonialism" 256). Asignarle a La Araucana arranques sediciosos se complica de partida con el hecho de que Ercilla no adopta retóricamente una actitud de antagonismo hacia el proyecto imperial - como matiza con acierto Durandó del modo que Bernal sí lo hace frente a Gómara y Cortés.
}

"Pastor reconoce en su brillante lectura que las limitaciones de la "restitución simbólica" (518519) que Ercilla ejecuta en su retrato idealizado de los araucanos serán superadas por el Inca Garcilaso de la Vega, a quien corresponderá la "recuperación auténtica del pasado indígena y su incorporación real a la historia" (518). 
Ercilla oscila entre su presentación del indio como ideal y su caracterización como ser capaz de una abyección e irracionalidad extremas; entre aquél encarnado en la figura de Caupolicán, fuerte, sereno y heroico, y la de Tucapel, violento, iracundo y enconado (aunque no menos valiente). ${ }^{12}$ Así mismo, su representación de Arauco alterna entre aquella de utópico locus amoenus digno de enmarcar grandes eventos históricos y la de territorio oscuro e inaccesible, escenario de bárbaras atrocidades y ceremonias paganas. En La Araucana, estas dos facetas no se encuentran desvinculadas sino, muy por el contrario, forman parte de una única labor de codificación, la cual limita una lectura del poema como procedente de una "conciencia escindida", término que se aplica con mayor propiedad a los lectores criollos - antiguos y contemporáneos- de La Araucana. Observemos, de paso, que esta caracterización dual tampoco está ajena al prurito erciliano de ser y parecer veraz: el lado bárbaro del retrato compensaría los posibles excesos de su evidente idealización.

\section{UNA MISMA COSA CON LA VUESTRA: EL ENEMIGO-COMPATRIOTA DEL CRIOLLO OÑA}

El conocimiento originado en la experiencia histórica personal y cercana es representado en ocasiones por Ercilla por medio de una cuidadosa combinación de voces y puntos de vista, algunos de ellos asignados a los personajes araucanos. ${ }^{13} \mathrm{Sin}$ embargo, esto no implica, obviamente, la existencia de algún tipo de diálogo real, ni mucho menos

${ }^{12}$ Esta dicotomía es precisamente la que Lope de Vega utiliza en su auto sacramental La Araucana, en la que la figura de Caupolicán adquiere rasgos cristológicos, mientras que Tucapel (cuyo nombre deforma en Teucapel) y especialmente Rengo son asociados con el demonio. En el teatro, es Lope el que con más fuerza ha refaccionado los personajes y situaciones generados por Ercilla. El Brasil restituido, El nuevo mundo descubierto por Colón, Arauco domado y el auto sacramental La Araucana confirman su interés por lo indiano, manifiesto en el resto de su obra. En el acto sacramental, el legendario Caupolicán logra sostener un pesado madero (alusivo a la cruz) por tres días. El auto concluye con todo el elenco reunido en apoteosis para celebrar el triunfo de las fuerzas del bien sobre las del demonio Rengo. En el banquete final, el dogma de la Transubstanciación de la eucaristía se ilustra a través de una imagen antropofágica, lo que da una idea de la atmósfera delirante que Lope le imprime a su obra: en la consagración, Caupolicán dice: "Pan de los cielos os traigo,/Que en leche los pechos puros/De una virgen lo amasaron;/Y por ver que sois amigos/De carne humana hoy os hago/Plato de mi carne misma/iMirad si es sabroso plato!" (La Araucana 287-88). Lope asimila cabalmente la ambivalencia que Ercilla ha inscrito en su retrato de los araucanos, y la lleva a sus límites máximos, yuxtaponiendo el sacramento de la eucaristía nada menos que con la antropofagia, característica bárbara por excelencia.

${ }^{13}$ En esto se aprecia claramente la influencia de la preceptiva enunciada por Pinciano: “[En el poema heroico] el poeta deue hablar lo menos que él pueda; ... Del narrar la cosa por persona agena del poeta nacen muchas cosas buenas a la acción; primeramente que, hablando assí, le es más honesto el alabar o vituperar las cosas que ama y aborrece, y dar su sentencia y su parecer más libre; lo otro que, dichas por vna y otra persona, varía la lección y no cansa tanto como si él solo fuesse el que narrasse" (Philosophia antigua poetica III 208-209). 
que el indígena sea representado desde un punto de vista americano, o "diferente". ${ }^{14}$ Es evidente que el poeta mantiene un control muy exclusivo del discurso, y más aún, paradójicamente, en esas ocasiones en que simula compartir la tarea de narrar. ${ }^{15}$ Pero en parte gracias a la inclusión de estas ficticias voces araucanas, el Poeta logra la ilusión de la guerra de Arauco como epopeya compartida que ha dado pie a las lecturas "americanistas". Este hábil simulacro de inclusión compensa eficazmente el escaso acceso de Ercilla al territorio mismo de Arauco, concediéndole a su discurso un grado de autoridad que se suma al de su participación personal en la guerra. ${ }^{16}$ Pedro de Oña, en cambio, escribe su Arauco domado en la corte de Lima careciendo de la autoridad que le había sido otorgada a su antecesor por su participación más directa en la guerra fronteriza. El poeta criollo, en un gesto diametralmente opuesto al de Ercilla, suple esta deficiencia recurriendo a su conocimiento más cercano del entorno geográfico y cultural de Arauco, adquirido durante su niñez y adolescencia en la ciudad-fuerte de Angol. Oña construye su auctoritas con elementos que amplían sustancialmente el papel que Ercilla les había asignado a los araucanos. Éstos ya no son meramente los portentosos y bárbaros enemigos retratados en La Araucana, sino que también funcionan como fuentes de información y de legitimación del conocimiento del autor. Recordemos que Ercilla aduce que sus fuentes historiales son imparciales y que provienen de "ambas partes" (I, XII, 69), expresión que podría llevar a engaño: con "ambas partes", Ercilla se refiere a la pugna entre los primeros conquistadores y los peninsulares recién llegados, es decir, entre baquianos y chapetones, más que a la guerra entre españoles y araucanos. Para confirmarlo, parece aludir a un cotejo de fuentes escritas, ajenas a la tradición indígena: "y pongo justamente sólo aquello/ en que todos concuerdan y confieren/y en lo que en general menos difieren" (I, XII, 69). Dicho apoyo en la historia escrita se reafirma aún más con su famosa mención de la crónica desconocida de Calvete de Estrella.

En el Arauco domado, en contraste, Oña invoca un conocimiento de índole claramente oral y, lo que es más radical, un conocimiento oral que está mediado a través del lenguaje araucano. Esta conjunción de terreno lingüístico con territorio geográfico presentada

\footnotetext{
${ }^{14}$ Para que existiera diálogo en el sentido profundo sería necesario, como puntualiza Donald Fanger, "not simply a dialogue of characters but of languages, social forces, genres, and historical times" ("Dostoevsky and Cervantes in the Theory of Bakhtin: The Theory of Bakhtin in Cervantes and Dostoevsky" 62).

${ }^{15}$ Avalle Arce ha observado algo similar con relación a las "sistemáticas intromisiones del Poeta en su relato" para establecer su dominio de la materia, comparándolo con Ariosto:

"El dominio del Poeta sobre su materia es tal que se puede permitir el lujo de poetizar ... dudas y su respuesta .... O sea que con el fin de ejercer dominio artístico absoluto sobre su materia épica, y demostrarlo, el Poeta ha creado un contrincante polémico fingido con el solo fin de aplastarlo dialécticamente ("El poeta en su poema (el caso Ercilla)" 162-63).

${ }^{16}$ Desde el comienzo del poema la tierra de Arauco se caracteriza como territorio vedado e ignoto: "Por falta de pilotos, o encubierta/causa, quizá importante y no sabida,/esta secreta senda descubierta/ quedó para nosotros escondida;/Ora sea yerro de la altura cierta,/ora que alguna isleta, removida/del tempestuoso mar y viento airado,/encallando en la boca, la ha cerrado" $(I, I, 9)$, hasta el final de la segunda parte (cantos XXXV y XXXVI), donde se narra la azarosa incursión de unos soldados españoles que se extravían en el "término de Chile señalado / de do nadie jamás pasado había" (II, XXXV, 4).
} 
por Oña expande considerablemente la profundidad de la visión de Arauco, introduciendo una novedosa yuxtaposición cultural totalmente ausente en La Araucana:

\author{
Helo sabido yo de muchos dellos \\ Por ser en su pays mi patria amada \\ $Y$ conocer su frasis, lengua y modo \\ Que para darme crédito, es el todo \\ (Arauco domado II, 27, énfasis mío).
}

Ercilla había construído una imagen del territorio de la guerra araucana en la que "Chile" y "Arauco" se enfrentan, formando una zona de gravitación mutua en cuyo centro se sitúa, dominante, el Poeta. Para Ona, las coordenadas del territorio, al que se refiere reiteradamente como "patria chica", lo sitúan sin equívocos dentro de los ambiguos linderos del país araucano. Su conceptualización del territorio está íntimamente ligada a los indígenas, como en Ercilla, pero de un modo sustancialmente diferente: Oña les atribuye a los indígenas parte de su propio conocimiento histórico e incluso un acervo lingüístico. Explica su uso de vocablos indígenas de la siguiente manera:

Van mezclados algunos términos Indios, no por cometer barbarismo, sino porque, siendo tan propria dellos la materia, me pareció congruencia que en esto también le correspondiesse la forma ("Prólogo al lector", énfasis mío). ${ }^{17}$

Ercilla aduce, en cambio, que su propia inclusión de "vocablos o nombres de indios" obedece simplemente a su deseo de darle variedad a su léxico, lo que justifica, además, señalando la adopción de estos términos por parte de los españoles que viven en el Nuevo Mundo:

Porque muchos no entenderán algunos vocablos o nombres (que aunque de indios, son ya tan recebidos y usados en aquella tierra de los nuestros que no los han mudado en nuestro lenguaje) será bien declararlos aquí porque como yo, por variar, uso alguna vez dellos, el que leyere este libro no tenga que preguntar ("Declaración de algunas dudas que se pueden ofrecer en esta obra" La Araucana 411 ).

Ercilla subraya así la separación entre esos "vocablos o nombres" indígenas y el castellano, lo que desvincula definitivamente la lengua de los araucanos (la "forma") de la gesta

\footnotetext{
${ }^{17}$ Rolena Adorno señala que Oña, con esta advertencia, busca justificar ante el lector europeo su inclusión de vocablos indígenas, los que explica como resultado de su deseo de ser verosímil ("Literary Production and Supression: Reading and Writing about Amerindians in Colonial Spanish America," 5). Como se verá más adelante, el uso del lenguaje araucano es más bien limitado, y si bien es cierto que puede ser usado como recurso de verosimilitud, creemos que la función principal que tiene la lengua nativa es la de servir de emblema del conocimiento que Ona tiene sobre su materia.
} 
épica (la "materia"). ${ }^{18}$ No es casualidad que en el breve compendio de palabras al final de La Araucana -en su mayoría simples toponímicos de uso frecuente- se encuentren términos que no provienen del mapudungun, sino de otras lenguas americanas. Oña, en contraste, les adjudica parte a los araucanos tanto en la forma como en la materia, haciéndolos partícipes - aunque sea sólo en potencia e indirectamente- del registro de su experiencia histórica. Insiste en la adjudicación a los araucanos de la "materia" al titular su propio glosario "Tabla por donde se entiendan algvnos términos proprios de los Indios, que en este libro (por tratar materia propria suya) se hallarán, supuestos los que ya van a la margen, y (como ya sabidos) los declarados en la tabla de la Araucana" (336, énfasis mío).

Pero no estará desacertado quien señale que a pesar de esto, en el Arauco domado la presencia concreta de la "frasis, lengua y modo" araucanos, siendo mayor que en $L a$ Araucana, es también muy limitada. La relativa escasez de términos indígenas en el poema parecería indicar que la invocación a la presencia de la lengua araucana en su obra es una operación retórica para compensar su relativa falta de credibilidad sobre los asuntos de la guerra de Arauco. Lo relevante no es la cantidad de vocablos sino la asociación radical que Oña efectúa entre lengua y patria (la "chilena frasis" dirá en el canto VII, 11), vínculo que por supuesto nunca se manifiesta, ni remotamente, en La Araucana. ${ }^{19}$ En Oña, la identidad patria germinal está configurada en torno a la imagen del araucano como aliado indispensable en el convenio de representación de las cosas de Chile, de la patria. Sin embargo, la alianza simbólica del criollo con el indio está preñada de una nueva y profunda tensión, desconocida para Ercilla: el araucano, es visto simultáneamente como compatriota y enemigo. Es considerado compatriota porque comparte el territorio de la Patria, Arauco/Chile; el acervo común es lo suficientemente cercano como para que se produzca una contaminación lingüística que no es tópica ni funcional, como en Ercilla, sino que tiene un entronque concreto y preciso en la vida de Arauco. ${ }^{20} \mathrm{El}$ araucano es enemigo a la vez que compatriota precisamente porque ócomo

\footnotetext{
${ }^{18}$ Para Claudio Guillén, los términos se relacionan de la siguiente manera: "I can only recall briefly that in the Aristotelian system form and matter are the two intrinsic "causes" that account for the mode of being of an object. As the object is analyzed after it has been made, an effort of abstraction is needed in order to distinguish between the two elements that have gone into its making: the matter of which the object was made; and the form, or principle of informing and structuring, which made it the actual object that it is" (Literature as System 110-111).

${ }^{19}$ Las implicaciones con respecto a la teoría poética son evidentes si se consideran los preceptos en torno a la Verdad enunciados por Mazzoni en su Della difesa della Commedia di Dante (1587): "When the events have happened in the present time and in the country of the people in whose language the poem is written, then the poet cannot depart from the truth, for he would openly be called a liar" (citado por William Nelson, Fact or Fiction. 44).

${ }^{20}$ Un ejemplo del corto glosario redactado primorosamente por Oña ilustra esta observación: "Vlpo, que los indios llaman (si se puede escribir) Vlldpu, es el principal, y más ordinario mantenimiento dellos, el qual solamente es harina de mayz o ceuada tostada, desleyda en agua fría, sírueles de comida, y bebida juntamente, y desto hacen su cocauí, o matalotaje, quando caminan, lleuando vna talega $\mathrm{d}[\mathrm{e}]$ esta harina, y vn cestillo para hacer el Vlldpu, tan texido, que nunca el agua echada en él se vierte ni reçuma. Es alimento muy fresco, y más sustancial y regalado cuando la harina lleua de
} 
soberano político y lingüístico de ese territorio que representa metonímicamente la totalidad del Reino de Chile - le impide al criollo asentarse con comodidad en su tierra natal. El título mismo del poema de Oña, que la crítica se ha empeñado en asociar exclusivamente con el sabido móvil de adular a García Hurtado de Mendoza, puede ser leído a esta luz como la refracción del anhelo del autor de efectuar una conquista de ese territorio a través de la palabra escrita, de reapropiar el nombre de la "patria cara",es decir, de domar por fin Arauco, aunque sea con la pluma.

Para el criollo Oña, esta "terrible empresa" que acomete parece consistir en un lucha constante por conciliar la materia con la forma, tema que atraviesa la obra desde el mismo prólogo hasta la "Tabla de vocabulario indígena". Esto se debe a que para él esta materia no se limita a las guerras de Arauco; su experiencia es más vasta que una gesta guerrera que espera ser vaciada en moldes épicos; está formada además por fuertes vivencias personales tan variadas como íntimas. Dentro de ellas está la comunión territorial y lingüística con el enemigo compatriota, relación que infringe fundamentalmente las condiciones básicas de la confrontación épica tradicional. La oposición entre las dos naciones, tan cuidadosamente elaborada por Ercilla, se desvirtúa en el Arauco domado a través de la noción, subyacente a lo largo de la obra, de que Arauco es un territorio compartido. Esta noción se articula alrededor de la borrosa figura del poeta que, al contrario del poeta-atalaya de La Araucana, no se constituye en centro de la acción sino que se instala a veces en un lugar de observador marginal. Pero aun desde este margen - o acaso precisamente por ubicarse en él- modifica la representación del territorio de guerra: Arauco ya no es sólo el finis terrae, el terreno de la utopía, el escenario épico donde se obtiene la gloria, sino además, y primordialmente, un entorno vital: una materia propia. Como resultado de la comunión cultural —ya que no espiritual- del poeta Oña con los cohabitantes de Arauco se forma un implícito vínculo ético; es éste el que se vulnera con la confrontación bélica. Para Oña, sin embargo, si la "materia" es copiosa y le pertenece por su vínculo personal con el territorio, la "forma" épica — herencia obligada de Ercilla - resulta insuficiente e incómoda. Esta incomodidad frente a la épica se manifiesta a través de una intensificación de aquellos registros poéticos —el pastoril, por ejemplo- que se evaden del tono épico y lo llegan a desplazar. ${ }^{21}$

Pero Oña no siempre se escapa de esta manera tangencial a la restricción discursiva que le impone la épica erciliana. Hay ocasiones en que su poema adopta un innegable tono heroico, el que sin embargo se ve transformado por el contexto discursivo en que ubica la acción. El peculiar punto de vista traído por Oña a la épica araucana se ve con

aquel Madi, que arriba se declara. De la calidad de la Frutilla no trato, porque el ser tan regalada, y rica fruta, pienso que la tiene dada a conocer por toda la tierra" ("Tabla por donde se entiendan algvnos términos proprios de los Indios" 336, énfasis mío). Ese breve "si se puede escribir" revela la inseguridad discursiva del poeta criollo, quien vacila ante los límites de lo permisible en la representación de su tierra.

${ }^{21}$ Eduardo Solar Correa, sin llegar a articular el problema, lo describe acertadamente: "Olvida el autor, en ocasiones, que escribe una obra épica, y el poema se convierte en égloga. En realidad, no son los indios quienes hablan: es el lírico que, oculto bajo férrea armadura, rebasa por sus bocas y dice sus amores" (Semblanzas literarias ... 67, énfasis mío). 
singular claridad en la escena del castigo a Galvarino, quien, capturado y a punto de ejecutarse el cruel castigo de cortarle las manos, increpa elocuentemente la cobardía y servilismo de los indios "amigos" de españoles. Observemos, para contrastar, que Ercilla oculta con una elipsis parte de las palabras de su Galvarino: "Diciendo así otras cosas que no cuento/ partió de allí ligero como el viento" (XXII, 53). Para extender la comparación, es importante señalar además que Ercilla, aunque se asombra de la entereza del guerrero de las manos cortadas, no lo presenta con admiración. Se refiere a él como "contumaz y porfiado", "rabioso y obstinado" (II, XXII, 49), "encarnizada bestia fiera" (XXII, 50) "bárbaro infernal" (XXII, 52) y agrega que, enloquecido de rabia, casi mata a dentelladas a un esclavo. Además, y esto no deja de ser significativo, en La Araucana, la increpación trunca de Galvarino a seguir resistiendo después de su castigo tiene lugar a su regreso entre los araucanos, y no tiene más testigos que los otros indios.

Oña, en cambio, presenta la situación narrativa de tal manera que los del bando español se convierten en silentes espectadores de la increpación de Galvarino. La voz del guerrero es tan elocuente que acalla a todos los que escuchan, no sólo a los avergonzados "compatriotas" yanaconas a quienes se dirige, sino a los mismos conquistadores, que no parecen atinar a responder. Galvarino toma posesión con fuerza de la voz poética, expresando conceptos y sentimientos acerca de la patria que sólo a la figura de un araucano le es permitido articular:
No dexo de morir con alegría
Muriendo por la dulce patria mía, Que es vna misma cosa con la vuestra;
Y no es mi voluntad llamarla nuestra
Por no contarme en vuestra compañía,
Ni conceder, o Chile que te llames
Engendrador de hijos tan infames (XII, 187). ${ }^{22}$

Pero no es sólo el contenido del discurso, con su delicado y bien razonado tratamiento del problema de la "patria", lo que hace que el episodio del suplicio de Galvarino se destaque dentro del Arauco domado. La escena del castigo a este legendario guerrero se organiza en torno a una situación narrativa que en efecto desmonta la cuidadosa separación de ámbitos territoriales y culturales elaborada por Ercilla. Ya hemos mencionado que en La Araucana la alocución de Galvarino se hace en territorio enemigo, mientras que en el

\footnotetext{
${ }^{22}$ Fernando Alegría expresa admiración por este pasaje, considerándolo una excepción en toda la obra: "Dificilmente podrá hallarse una expresión más poderosa y henchida de genuina indignación en otro poeta espanol de cualquier época. Hace pensar en los versos más combativos de los tiempos modernos, en el odio social de un César Vallejo, en los anatemas de Neruda contra los generales fascistas .... Su tono es épico y nada tiene que envidiar a lo mejor de Ercilla .... ¿Cómo explicar el fervor que le coge de pronto y la emoción que va creciendo gradualmente, y la palabra sincera y dura, absolutamente extraña en su vocabulario humanista y pastoril?" (La poesía chilena 62-63). Concurrimos en que se trata de una ocasión excepcional, pero no sólo por el contenido de la increpación de Galvarino, sino por la situación discursiva en que Ona emplaza la escena, como se detalla más adelante.
} 
Arauco domado tiene lugar en tierra de nadie, en un terreno de disputa. Además, en el episodio narrado por Oña los bandos en escena son, a primera vista, por lo menos tres: el de los araucanos libres, el de los "hispanos" (XII, 30) y el de los indios amigos. A ellos se agrega implícitamente - más silente que todos los otros, pero de crucial importanciaun cuarto estamento, el del criollo. Los españoles nacidos en Chile tienen puntos de contacto con cada uno de los grupos explícitamente representados en el cuadro escénico: con el conquistador, su "nacionalidad" española; con el yanacona, la "patria" y su posición de dependencia con respecto al español; ${ }^{23}$ con el araucano indomable cuya epítome es el manco Galvarino, la "patria" y la palabra elocuente que le concede. De esta manera, el estamento criollo, el de Oña mismo, se insinúa tras las efigies de los demás actores que ponen en escena las contradicciones propias de su grupo social. El Arauco domado, a este nivel discursivo, no es tanto la representación de una gesta heroica como la puesta en escena de una pugna sorda por el territorio natal, la cual un criollo como Oña sólo puede representar de modo oblicuo, a pesar de estar involucrado tan directamente en ella.

Otro criollo chileno, Francisco Núñez de Pineda y Bascuñán hallará en el discurso de Ercilla y en la transformación de Oña los materiales simbólicos con que intentará darle sentido a su experiencia personal en las guerras de Arauco, vertida en su Cautiverio feliz (1673). De Oña, Pineda, al igual que sus descendientes chilenos, aprenderá el modo paradójico en que el poeta criollo se adueña de la figura del indio con el fin de legitimar su propio conocimiento de las cosas de la "patria" que con él comparte, apropiación marcada por el emblema contradictorio de la elocuencia impotente del manco Galvarino. Paradójicamente, al asignarle al araucano la voz que mejor defiende la identidad patria, el criollo renuncia a articular su propia identificación con el territorio natal. La contradicción discursiva de la que surgen los textos de los dos criollos (el poeta cortesano en busca de reconocimiento y el viejo soldado en busca de recompensa) se refleja en la paradoja de los títulos de sus obras - Arauco domado, Cautiverio feliz-los que remiten a entidades inexistentes o problemáticas. El signo del ocultamiento oscilante impuesto por Ercilla a los araucanos es el "grado cero" del que parten Oña y Pineda, quienes reproducen, modificándolo, su gesto encubridor de dos caras. En sus obras, la identificación con el araucano patriota resulta en un paradójico ocultamiento de sí mismos, y configura un espacio autobiográfico sustancialmente diferente al del chapetón Ercilla. El discurso criollo parece condenado a constituirse con las cifras heredadas de La Araucana para poder legitimarse como algo "propio", y así, para tener derecho a Arauco, el chileno, sea nacionalista o americanista, conservador o revolucionario, debe disfrazarse del Caupolicán de Ercilla, aun cuando en realidad esté reproduciendo la compleja confrontación que se encuentra mejor representada en el Arauco domado de Pedro de Oña.

${ }^{23}$ Esta dependencia frente al español no es sólo política: el éxito de la misión literaria que emprende Oña depende de su aceptación por parte del mundo de las letras españolas, mundo al que se acerca muy consciente de su marginalidad. Su amplio despliegue de elementos literarios -como el pastoril- que no pertenecen estrictamente a la épica proviene de su ansiedad frente a la tradición en la que quiere inscribir su obra. 


\section{ObRas CITADAS}

Adorno, Rolena. "Literary Production and Supression: Reading and Writing about Amerindians in Colonial Spanish America". Dispositio 11.28-29 (1985): 1-25.

Alegría, Fernando. La poesía chilena: orígenes y desarrollo del siglo XVI al XIX. México, Buenos Aires: Fondo de Cultura Económica, 1954.

Avalle-Arce, Juan Bautista. "El poeta en su poema (el caso Ercilla)". Revista de Occidente 95 (1971): 152-170.

"Pedro de Oña ante la epopeya". Filología 20.2 (1971): 160-170.

Bello, Andrés. Obras completas. Caracas: La Casa de Bello, 1982.

Bocaz, Aura. "El personaje Tegualda, uno de los narradores secundarios de La Araucana". Boletín de filología 27 (1976): 7-27.

Cevallos, Francisco Javier. "Don Alonso de Ercilla and the American Indian: History and Myth". Revista de Estudios Hispánicos 23.3 (octubre 1989): 1-20.

Durand, José. "Caupolicán, clave historial y épica de La Araucana". Révue de Littérature Comparée 2-4 (1978): 367-389.

"El chapetón Ercilla y la honra araucana". Filología 10 (1964): 113-134.

Ercilla y Zúniga, Alonso de. La Araucana. Marcos A. Moríngo e Isaías Lerner, editores. 2 volúmenes. Madrid: Clásicos Castalia, 1979.

Guillén, Claudio. Literature as System. Essays Toward the Theory of Literary History. Princeton: Princeton University Press, 1971.

Invernizzi Santa Cruz, Lucía. "La representación de la tierra de Chile en cinco textos de los siglos XVI y XVII". Revista Chilena de Literatura 23 (abril 1984): 5-37.

Jara, René. El revés de la arpillera. Perfil literario de Chile. Madrid: Ediciones Hiperión, 1988.

Lara, Horacio. Crónica de Araucanía. Leyenda heroica de tres siglos. Santiago de Chile: Imprenta de "El Progreso", 1889.

Lastarria, José Victorino. Recuerdos literarios. $2^{\mathrm{a}}$ edición. Santiago de Chile: Imprenta de M. Servat, 1885.

López Pinciano, Alonso. Philosophia antigua poetica. Madrid: Instituto Miguel de Cervantes, Consejo Superior de Investigaciones Científicas, 1953.

Oña, Pedro de. Primera parte de Arauco domado. Civdad de los Reyes [Lima]: Antonio Ricardo de Turín, 1596.

Pastor, Beatriz. Discurso narrativo de la conquista de América. La Habana: Casa de las Américas, 1983.

Perelmuter-Pérez, Rosa. "El paisaje idealizado en La Araucana". Hispanic Review 54.2 (1986): 129-146.

Rodríguez, Mario. "Un caso de imaginación colonizada: Arauco domado". Acta literaria 6 (1981): 79-92.

Sarmiento, Domingo Faustino. Conflictos y armonías de las razas en América. Tomo I. Buenos Aires: Imprenta de D.Tuñez, 1883.

Solar Correa, Eduardo. Semblanzas literarias de la colonia. Santiago de Chile: Editorial Nascimento, 1933. 
Valdivia, Pedro. Cartas al Emperador Carlos V. Colección de Historiadores de Chile, Tomo I. Santiago de Chile: Imprenta del Ferrocarril, 1861.

Vega, Lope de. Dos comedias famosas y un auto sacramental. Prólogo, introducción y notas de José Toribio Medina. Santiago de Chile: Sociedad Imprenta-Litografía Barcelona, 1917. 
